\title{
Balance crítico de cuatro partidos políticos (PCN, PDC, ARENA y FMLN)
}

Las elecciones de marzo de 1999 están cada vez más cerca; en consecuencia, a medida que este año vaya llegando a su fin, los campañas proselitistas irán arreciando al margen de los plazos legales establecidos para ello. El caso del partido Alianza Republicana Nacionalista (ARENA) es, a estas alturas, el más significativo, pues su candidato presidencial, Francisco Flores, se ha tomado en serio el desafío de acceder al ejecutivo. En el otro polo, el partido Frente Farabundo Martí para la Liberación Nacional (FMLN) está empeñado en retrasar a más no poder su irrupción en el escenario preelectoral; el entrampamiento en la elección de su fórmula para la presidencia y la vicepresidencia de la república le está restando un tiempo que será valioso a la hora de querer convencer a los votantes indecisos.

Por su parte, el Partido de Conciliación Nacional (PCN) no da señales de estar preocupado por el desenlace de 1999; seguramente tiene afincadas sus esperanzas en un empate en la primera vuelta entre ARENA y el FMLN, el cual le permitiría respaldar con sus votos duros, previa negociación, las candidaturas del primero. Por último, el Partido Demócrata Cristiano (PDC) que, con la emergencia de los antiguos liderazgos pedecistas - encabezados por Alejandro Duarte-, ha visto cuestionada no sólo la autoridad de Ronal Umaña, sino el compromiso de la democracia cristiana con ARENA. Si en el Partido de Conciliación Nacional el posicionamiento ante las elecciones del próximo año no trasluce mayores dificultades, en el Partido Demócrata Cristiano el panorama es sombrío, en cuanto a que los viejos liderazgos parecen estar empeñados en asumir - a diferencia de Umaña, quien al parecer se conforma con ser un subordinado de ARENA - un papel protagónico en la vida política nacional.

Salvo la emergencia fortuita de un bloque de centro - hasta ahora los intentos por construirlo han terminado en fracaso-, nada parece indicar que los cuatro partidos más importantes en la historia política reciente de El Salvador vayan a dejar de ocupar un lugar de primera importancia en el escenario que se creará en torno a las elecciones presidenciales de 1999. En este comentario pretendemos contribuir al debate sobre los partidos políticos que, para bien o para mal, van decidir —en virtud de su oposición o sus alianzas-- el estilo de gobierno que tendrá el país cuando se inicie el tercer milenio. En siete tesis, en lo absoluto exhaustivas, se describen los principales rasgos y trayectoria de los cuatro partidos políticos más importantes de El Salvador.

Primera tesis: los partidos PCN, PDC, FMLN y ARENA han jugado un papel decisivo en la vida politica nacional durante las últimas tres décadas. En la década de los años setenta, el Partido Demócrata Cristiano fue -integrado junto con el Movimiento Nacional Revolucionario (MNR) y la Unión Democrática Nacionalista (UDN) en la Unión Nacional Opositora (UNO)- el principal partido de oposición, mientras que el partido en el poder era el Partido de Conciliación Nacional apoyado por el estamento militar. Fue, por un lado, la época heroica de la democracia cristiana; la época i en la cual no sólo la apuesta popular por las elec- 
ciones se vino abajo, dadas las resistencias militaristas al cambio político, sino en la que afloró lo mejor de la resistencia civil (pacífica) al autoritarismo. Se trató, por otro lado, de una época dominada por la alianza entre el PCN y las élites militares, que utilizaban el aparato del partido para movilizar un apoyo popular que, bajo la bandera de la Organización Democrática Nacionalista (ORDEN), adquirió un carácter paramilitar. Si la UNO —cuyos líderes más representativos fueron José Napoleón Duarte (PDC) y Guillermo Manuel Ungo (MNR) - representaba el polo de resistencia al autoritarismo, el PCN —en cuya cúpula estaban figuras militares de alto rango- representaba el polo autoritario, es decir, el polo de la exclusión política y la ausencia de libertades civiles fundamentales.

En la década de los ochenta, el Parrtido Demócrata Cristiano - hasta 1989-desempeñó una función de primera importancia en la conducción del gobierno y en la lucha contrainsurgente -a través de un pacto PDC-FFAA-Administración Reagan-Bush-, mientras que el FMLN le apostaba, como ejército insurgente, a la toma del poder político mediante la lucha armada. Se trató, por un lado, de una época de gloria de la democracia cristiana. El poder que le había sido arrebatado, primero a Duarte (1972) y luego a Ernesto Claramount (1977), al fin se había conquistado, aunque no precisamente a través de la urnas, sino mediante un pacto con los tan odiados militares. El PDC se alió con sus enemigos de antes y atacó frontalmente a quienes había dicho defender: los sectores populares organizados. Ciertamente, fue la época de gloria de la democracia cristiana, pero fue también una época de vergüenza. El partido llegó al poder, con Duarte a la cabeza, pero el costo que tuvo que pagar no fue insignificante: haber asumido la conducción de uno de los gobiernos más criminales de la historia contemporánea de El Salvador.

Ese fue el (triste) papel que se le asignó al PDC en el esquema contrainsurgente de baja intensidad diseñado por la administración ReaganBush para combatir al FMLN. Este último, por otra parte, no sólo resistió a la embestida que siguió a la "ofensiva final" del 10 de enero de 1981, sino que, a lo largo de la década, se consolidó como un ejército capaz de resistir y, en más de una oportunidad, poner en aprietos a la Fuerza Armada. Hasta 1989, el PDC representó el polo polí- tico de la guerra contrainsurgente, mientras que el FMLN a la vez que se tecnificó militarmente se aisló de amplios sectores sociales, reacios tanto a comprometerse en el esquema de confrontación como a continuar cargando con los costos de una guerra a la que no se le veía una solución a corto plazo.

Al cierre de 1989 se hizo evidente, en los planos nacional e internacional, que la guerra civil no podía ni debía continuar, dado el virtual empate de los bandos enfrentados, el cansancio de la población y la fractura económica que el conflicto había provocado. Lo irracional de la guerra civil se hizo patente con el asesinato de los jesuitas de la Universidad Centroamericana "José Simeón Cañas", el 16 de noviembre de 1989. Como resultado del múltiple asesinato, el clamor pacificador cobró tal fuerza que, pese a los arrebatos militares tanto del FMLN como de la Fuerza Armada, la paz pudo firmarse en 1992. Se inició así una nueva fase en el proceso de transición democrática, marcada por la conversión del FMLN en partido político. Desde ese momento hasta ahora - tras haber participado en dos eventos electorales (1994 y 1997)-, el Frente se ha convertido en la segunda fuerza política del país, detrás del partido ARENA. Mientras tanto, el PCN y el PDC, tras su sensible disminución de poder, han terminado por conformar con ARENA un bloque de derecha, por lo cual obtienen una serie de beneficios políticos y económicos.

Segunda tesis: cada uno de los cuatro partidos ha atravesado por una serie de reacomodos que, en más de una oportunidad, se han decantado hacia crisis y rupturas internas. Los partidos que más se han debilitado en razón de esas crisis y rupturas son el PCN y el PDC, aunque ciertamente a ARENA y al FMLN no les han sido ajenas las dificultades creadas por las disidencias, como lo revelan las críticas que ciertos sectores de derecha lanzan contra ARENA y el gobierno - los que acusan de ser mercantilistas-, y la difícil situación por la que está pasando en estos momentos el FMLN para definir su fórmula electoral. De todos modos, las crisis y rupturas internas por las que han pasado —o están pasando en la actualidadlos cuatro partidos políticos aludidos no los han fortalecido sino que, más bien, los han debilitado, tanto por la fuga de cuadros como por los conflictos entre facciones en las que se han aglutinado los grupos de interés. 
Tercera tesis: el PCN enfrentó su situación más dificil en octubre de 1979, cuando una junta revolucionaria de gobierno puso al descubierto la represión y la corrupción propiciadas por ese partido. Es decir, octubre de 1979 no sólo marcó el fin del predominio político pecenista, sino que también sacó a la luz pública lo nefasto que había sido para la institucionalidad del país la alianza de ese partido con el estamento militar. Los vicios del partido, su vocación antidemocrática y el compromiso de sus dirigentes con los grupos de poder se hicieron evidentes para todos, sin que quedara la menor duda de que el cambio político democrático había encontrado en el PCN a uno de sus enemigos declarados.

A partir de 1979, el PCN - que había controlado el poder desde los años sesenta - no volvió a acceder al control del gobierno. Era difícil que pudiera hacerlo, dada la deslegitimación popular que lo acompañó incluso desde antes de su ruptura con los militares y los grupos de poder económico. A fines de la década de los años setenta y principios de la década de los ochenta, no sólo dio inicio la separación entre los militares y el partido, sino que - en el contexto de una guerra que se anunciaba- muchos de sus miembros civiles optaron por abandonar sus filas o retirarse de la vida polí-

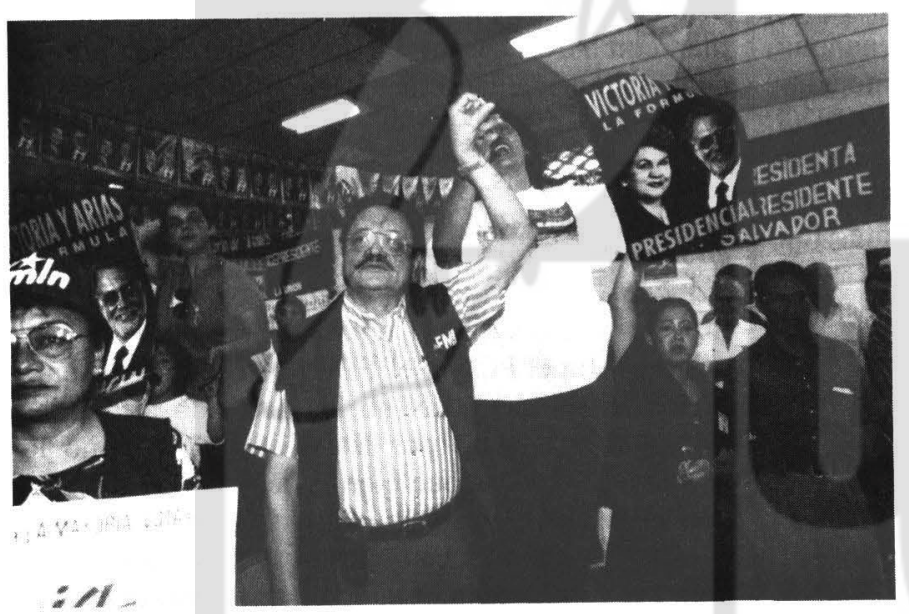

tica a la espera de tiempos mejores. Quienes continuaron como políticos activos - los que ahora controlan la cúpula pecenista - aceptaron el desplazamiento del PCN, como el partido de derecha por antonomasia, por ARENA, al que se incorporaron varios ex militantes pecenistas o al que se subordinaron la mayoría de cuadros dirigentes que continuaron regentando lo que quedaba del partido.

Cuarta tesis: el PDC conoció con Napoleón Duarte, en los años ochenta, el sabor del poder político, del cual habia sido marginado fraudulentamente en la década anterior. Primero como presidente de una de las juntas revolucionarias de gobierno' y segundo como Presidente de la República — de 1984 a 1989—, Duarte pudo llevar a los miembros del partido a los puestos de mando en la estructura del Estado -ministerios y viceministerios-, con lo que se propició una corrupción nunca vista en la historia contemporánea de El Salvador. EI PDC hizo de las suyas, aun y cuando la resistencia de la clase empresarial fue manifiesta, amparado en el respaldo que le otorgaba el gobierno estadounidense y en la aceptación que a regañadientes había logrado por parte del estamento militar. El PDC luvo en sus manos el poder político que tanto había codiciado; Duarte, convencido que era el mesías que salvaría al país de la crisis, no dudó en aliarse con quienes en la década pasada lo habían enviado, previa paliza, al exilio. Cada una de las figuras pedecistas obtuvo lo suyo, tanto a nivel económico vía la corrupción generalizada - como a nivel simbólico - vía las alabanzas que les profesaban los que esperaban obtener algo de los magnates democristianos.

Muerto Duarte, se inició un conflicto por la sucesión que terminó por dar lugar a la formación de dos facciones: los "chavistas" —-seguidores de

1. Entre octubre de 1979 y febrero de 1982 hubo tres juntas revolucionarias de gobierno. La primera, que asumió el 15 de octubre de 1979, estuvo integrada por militares progresistas e intelectuales de izquierda. Fue presidida por el entonces Rector de la UCA, Román Mayorga Quiroz. Esta junta se desintegró en los primeros días de enero de 1980 y fue reintegrada por cuadros vinculados al MNR y al PDC. En febrero del mismo año se formó una tercera junta presidida por Napoleón Duarte, la cual se mantuvo en el poder hasta febreto de 1982, cuando se realizaron elecciones para Asamblea Constituyente y se nombró como Presidente provisional de la República a Alvaro Magaña. 
Fidel Chávez Mena- y los reyprendistas - los seguidores de Julio Adolfo Rey Prendes. El conflicto se generó en torno a quién iba a ser el candidato del partido para las elecciones de 1989; cada uno de los contendientes, apoyados por sus respectivas camarillas, aspiraba no sólo a controlar el aparato partidario, sino - una vez que hubiese ganado las elecciones - a gozar de los privilegios a los se podía acceder desde la presidencia de la república. Con Duarte pudieron disfrutar de beneficios hasta entonces desconocidos; muerto Duarte, se trataba de acaparar (o quedarse con) el máximo poder posible, aunque tan sólo fuera el control del aparato partidario (las propiedades, las finanzas, los vehículos, etc.).

Ambas fracciones se enfrascaron en un conflicto interminable; en el marco de ese conflicto se gestó el fracaso político de 1989, con el que acabó la época de gloria democristiana. El partido, desde luego, no se recompuso, sino que las facciones "tradicionales" fueron reemplazadas por dos nuevas fracciones: la "vieja guardia" (presuntamente formada por antiguos chavistas y reyprendistas) y la "nueva clase política" (presuntamente formada por líderes jóvenes del partido, ajenos a las conflictos que siguieron a la desaparición de Duarte). Son los dos últimos agrupamientos los que se han disputado el control del partido en los últimos cuatro años. Al igual que antaño, las prácticas más sucias caracicrizaron a ambas facciones, una de los cuales - la encabezada por Ronal Umañaterminó por desplazar a la otra.

Quinta tesis: ARENA, tras el fracaso del PCN, vino a llenar un vacio en las filas de los grupos de poder económico: contar con un partido que les pernitiera embarcarse de nuevo en la lucha politica electoral. El partido ARENA, una vez que comenzó a dejar atrás sus antecedentes escuadroneros, a principios de la década de los años ochenta, tuvo una marcha electoral ascendente; primero hacia la Asamblea Legislativa (1985 y 1988) y, después, hacia el ejecutivo: en 1989, Alfredo Cristiani (ARENA) relevó a Duarte en la presidencia de la república. Comenzó el reinado de ARENA, en un contexto en el cual el FMLN hacía sus últimos esfuerzos militares por hacerse del poder estatal. ARENA agrupó, frente a la amenaza del FMLN, a los tres sectores de poder económico: terratenientes, industriales y banqueros; los tres sectores formaron una unidad monolítica en torno a un propósito fundamental: contrarrestar la amenaza insur- gente. Cualquier fricción interna en el bloque de derecha era desechada, pues podía debilitarlo ante un enemigo común. Cuando la amenaza militar del FMLN desapareció, a raíz de la firma de los acuerdos de paz, los intereses de esos tres sectores comenzaron a generar fricciones en el interior de ARENA. A larga, el sector que animó la fundación del partido -el formado por los grandes productores agrícolas - fue desplazado por el sector bancario-financiero que se impuso, no sin intensos forcejeos en el seno del Consejo Nacional de ARENA (COENA).

Sexta tesis: El FMLN, de ejército guerrillero con estructuras de mano jerarquizadas y centralizadas, ha tenido que convertirse en partido politico, no sin dejar de atravesar por agudas crisis internas. En la década de los setenta, cinco fracciones expresaban las tendencias político-militares y marxista-leninistas existentes en el país: inicialmente el Ejército Revolucionario del Pueblo (ERP), las Fuerzas Populares de Liberación (FPL) y la Resistencia Nacional (RN); a ella se sumaron, posteriormente, el Partido Revolucionario de los Trabajadores Centroamericanos (PRTC) y las Fuerzas Armadas de Liberación (FAL). A inicios de la década de los ochenta, en el marco de una fuerte represión gubernamental contra el movimiento popular, esas fracciones fundaron el FMLN sin que desaparecieran sus diferencias de fondo, las cuales tenían que ver con cuál organización era la más auténticamente revolucionaria y con el rol asignado a los diferentes actores sociales y políticos -militares progresistas, profesionales, intelectuales, obreros y campesinos- en el programa revolucionario abanderado por cada una.

Finalizada la guerra civil, esas diferencias salieron nuevamente a flote. Esta vez, los problemas giraban en torno a cuál era la organización (con sus respectivos liderazgos) que debía hegemonizar el quehacer del nuevo partido. Estas disputas llevaron a que, por un lado, se aglutinaran las FPL, el PRTC y el Partido Comunista (de donde provenían las FAL), con el FMLN —aparato partidario, símbolos y tradiciones-; mientras que, por el otro, el ERP y la RN - abanderadas de un día para otro de una concepción socialdemócrata bastante peculiar- decidieron fundar un nuevo partido: el Partido Demócrata (PD), cuya presencia política es irrelevante. Con la formación del PD, todo parecía indicar que la tranquilidad interna llegaría al FMLN, pero no fue así: una nueva divi- 
sión afloró en sus filas: la división entre "ortodoxos" (a cuya cabeza se sitúan Schafick Handal y Leonel González) y "renovadores" (cuya principal figura es Facundo Guardado).

Séptima tesis: el impacto de las mutaciones partidarias (recambios, crisis y rupturas) sobre la sociedad tiene dos niveles, que se entrecruzan para alimentar la percepción social de que la política y los politicos sirven de poco al proceso de democratización en El Salvador. El primero de los niveles señalados tiene que ver con el impacto de las dinámicas partidarias sobre la intelectualidad más optimista del país, la cual, en general, suele ver esas mutaciones como señal inequívoca de la democratización en la que están inmersos los partidos políticos. Entre los intelectuales optimistas, por supuesto, las opiniones se dividen según sean las simpalías partidarias: al partido de las preferencias se le atribuyen las bondades más anodinas; al partido odiado se le achacan los peores males. Un sector intelectual más crítico no se conforma con las apreciaciones apuntadas, y prefiere interpretar la dinámica de los partidos políticos, en ge- neral, como expresión de un déficit en su democratización interna y en la democratización del sistema político.

El otro nivel de impacto hace relación con los grupos sociales mayoritarios que, como lo revelan innumerables sondeos de opinión, no alcanzan a entender qué es lo que sucede en el ambiente político; el resultado práctico de ello es la incredibilidad y la desconfianza hacia la política y los políticos. De aquí que el gran reto de los partidos políticos en vistas a marzo de 1999 , sea convencer a estos grupos sociales -que conforman el espectro de votantes indecisos - de que votar por uno de ellos no será, como en el pasado, tiempo perdido. Convencer a los convencidos es fácil; pero esto no bastará para ganar las elecciones del próximo año. ¿Cómo le harán nuestros políticos para borrar del imaginario social la percepción (no tan gratificante) que se tiene de ellos? Esa es la interrogante que tiene que ocupar a sus asesores en marketing y publicidad.

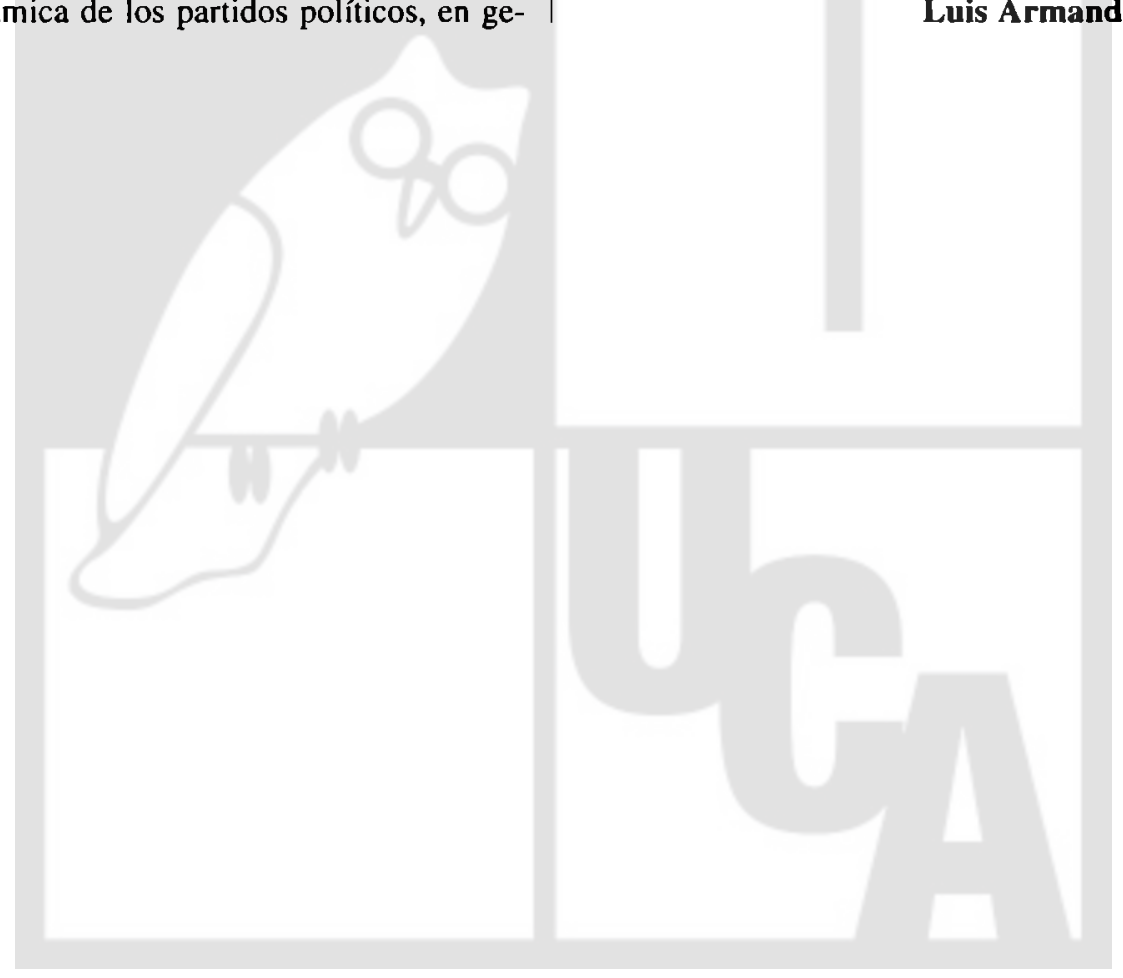

